\title{
AIRBORNE MEASUREMENTS OF THE VERTICAL FLUX OF OZONE IN THE BOUNDARY LAYER
}

\author{
D. H. LENSCHOW ${ }^{1}$, A. C. DELANY, B. B. STANKOV \\ National Center for Atmospheric Research ${ }^{2}$, Boulder, Colo. 80307, U.S.A. \\ and \\ D. H. STEDMAN \\ Department of Atmospheric and Oceanic Science, University of Michigan, Ann Arbor, Mich. 48109, \\ U.S.A.
}

(Received in final form 10 December, 1979)

\begin{abstract}
A fast-response chemiluminescent ozone sensor was mounted in an aircraft instrumented for air motion and temperature measurements. Measurements of the vertical flux of ozone by the eddy correlation technique were obtained after correcting for time delay and pressure sensitivity in the ozone sensor output. The observations were taken over eastern Colorado for two days in April, one a morning and the other an afternoon flight. Since the correlation coefficient of ozone and vertical velocity is small compared to, for example, temperature and vertical velocity in the lower part of the convective boundary layer, an averaging length of the order of $100 \mathrm{~km}$ was required to obtain a reasonably accurate estimate of the ozone flux. The measured variance of ozone appeared to be too large, probably mainly due to random noise in the sensor output, although the possibility of the production of ozone fluctuations by chemical reactions cannot be dismissed entirely. Terms in the budget equation for ozone were estimated from the aircraft measurements and the divergence of the ozone flux was found to be large compared to the flux at the surface divided by the boundary-layer height.
\end{abstract}

\section{Introduction}

Interest in atmospheric trace gas constituents has led to the development of instrumentation for quantitative mean measurements of these constituents. However, for an understanding of the role of these gases in atmospheric chemistry, the total budget must be defined. The time and space concentration distributions are not sufficient; the production and destruction rates, and transport must also be determined. The flux across the atmosphere/earth boundary is an important factor in the definition of these budgets and one which is difficult to determine. Methods involving the measurement of concentration changes in either static or recirculated volumes of air exposed to representative surfaces (the 'box method') are sometir es useful, but they define fluxes in either unrealistic or highly specific conditions. The most direct method employs the continuous simultaneous measurement of both concentration and vertical air motion (the 'eddy correlation method'). The vertical flux of ozone is the average of the product of instantaneous values of concentration and vertical velocity. The averaging must be over a sufficient length (or time) to incorporate all the scales of variation contributing to the flux and to obtain a stable

1 Part of this work was carried out while a visitor at Risø National Laboratory, Denmark.

${ }^{2}$ The National Center for Atmospheric Research is sponsored by the National Science Foundation. 
estimate. This technique requires fast response instrumentation capable of measuring concentrations with a time resolution sufficient to resolve the turbulent fluctuations effecting the transport and with an accuracy that can measure the differences in concentration of the constituent depending on the direction in which the air is moving. Flux measurements are useful both for quantitatively estimating sources and sinks of atmospheric constituents, and for studying boundary-layer evolution by use of tracers having different mechanisms of generation, transport and destruction.

In the case of ozone, instrumentation has been developed and used for turbulent fluctuation measurements (Eastman and Stedman, 1977). Instruments of this type have now been used to make direct eddy flux measurements of ozone from a fixed point in the atmospheric surface layer (Wesely et al., 1978). Here we discuss the use of a similar instrument on an aircraft, including application and interpretation of data, and comparisons with data from other sensors on the aircraft, as well as possible future applications of this and other sensors capable of measuring fluctuations of trace constituents. With an aircraft, measurements of fluxes and other turbulence statistics can be obtained over long averaging lengths at various heights above the ground in a relatively short time. However, the aircraft speed puts an even greater requirement on fast instrumentation response than fixed point measurements.

\section{Instrumentation}

The fast ozone sensor used was based on an original design by McFarland et al. (1979) of a detector intended for low concentrations of nitric oxide and ozone. By using a 'reversed' mode and supplying the instrument with pure nitric oxide, an extremely sensitive ozone detector was achieved (Stedman et al., 1972). Minimal gas sampling plumbing and faster electronics were used to increase the frequency response of ozone detection and to take advantage of this sensitivity.

The instrument was mounted in the cabin of an NCAR Queen Air aircraft. A flow system was devised to minimize the time delay in the ozone measurement by bleeding off a small volume of air through a short section of tubing connecting a $5 \mathrm{~cm}$ diameter manifold to the sensor. The manifold air intake was a forward facing $10 \mathrm{~cm}$ diameter scoop mounted atop the aircraft $5.9 \mathrm{~m}$ aft of the tip of the gust probe. Approximately $2501 \mathrm{~s}^{-1}$ of air passed through the manifold in the cabin to exit through a port in the belly of the aircraft. The sensor sampled $0.51 \mathrm{~s}^{-1}$ from this flow through a $26 \mathrm{~cm}$ length of $1 \mathrm{~cm}$ internal diameter Teflon tubing. Even with this fast flow arrangement, a time delay was introduced which had to be allowed for in the data analysis.

In these original experiments, we believed that the weight and power demand of a vacuum pump normally employed could be avoided by using aircraft venturis for suction. As the sensitivity of these chemiluminescence devices is directly proportional to flow/operating pressure, it was felt that no difference would ensue by using venturis at $0.51 \mathrm{~s} \mathrm{~s}^{-1} / 300$ torr rather than a vacuum pump at $0.0251 \mathrm{~s}^{-1} / 15$ torr. The instrument was calibrated for absolute ozone determination against an ultraviolet 
photoabsorption instrument and the response characteristics were defined. The sensitivity was found to depend upon flow pressure parameters according to the semi-empirical relationship

$$
\left[\mathrm{O}_{3}\right] \text { in ppb (by volume) }=\frac{0.002 \mathrm{P}}{\sqrt{\Delta P(2 P+\Delta P)}} N
$$

where $P$ and $\Delta P$ are the reactor pressure and the differential pressure across the reactor, both measured in torr, and $N$ is the ozone output in counts $\mathrm{s}^{-1}$.

This relationship applies when the pressures are constant or varying slowly with time. Venturi suction, however, is a function of aircraft attitude and airspeed, which can vary rapidly in a turbulent atmosphere. In this situation, dynamic effects are introduced; the ozone sensor output was observed to be affected by the time derivative of the differential pressure, as well as by its mean value. Since airspeed is, to some extent, correlated with vertical velocity, this dynamic pressure effect can affect the measurement of vertical ozone flux.

The aircraft was also instrumented with an air-motion sensing system which provided turbulent measurements of all three velocity components and mean horizontal winds. The system has been described by Lenschow et al. (1978). The sensors were mounted at the tip of a $2 \mathrm{~m}$ nose boom along with resistance wire thermometers which were used for both mean and turbulent fluctuations of air temperature. All the data used for turbulence measurements were filtered with $10 \mathrm{~Hz}$ 4-pole low-pass Butterworth filters and recorded digitally on magnetic tape at a sample rate of $20 \mathrm{~Hz}$. The time constants of the air motion and temperature sensors were sufficiently small that they had a negligible effect on the recorded data.

It would have been very desirable to avoid having to make corrections in the measured ozone concentration for flow rate and static pressure by holding these variables constant during flight. In-flight variations of these variables do, however, modulate the ozone sensor output and thus, by use of spectral techniques, permit us to determine the separate time delays of the ozone sensor and its associated ducting. This general procedure is useful whenever it is possible to measure a variable that modulates the input to a sensor in a simple way with sufficient amplitude to generate a significant coherence between the sensor output and the variable modulating the sensor.

Phase angles between raw ozone output and (1) the aircraft true airspeed, and (2) the differential ozone sensor pressure were computed using a Fast Fourier Transform. The phase angle between ozone and true airspeed is a measure of the overall time delay of the ozone measurement, while the phase angle between ozone and differential pressure in the sensing chamber is a measure of the time delay associated with the ozone sensor itself. The difference between the two is a measure of the time delay due to the intake ducting and the distance between the air intake and the airspeed sensor. This assumes that the phase angle between ozone and airspeed (or differential pressure) would be zero if each sensor had the same response characteristics. This assumption was checked by flying the aircraft at different headings to 
see if the phase angie was independent of aircraft heading. No change with direction was observed. Therefore, the phase angle between ozone and airspeed can be used as a measure of the time delay, provided the coherence between the two is large enough to obtain stable estimates of the phase angle (i.e., the variables must be well correlated over the range of frequencies of interest). Figure 1 shows that the coherence is $>0.5$ between ozone and airspeed up to $0.4 \mathrm{~Hz}$, and between ozone and differential pressure to $1.0 \mathrm{~Hz}$. This is sufficient to give stable estimates of the phase angles.

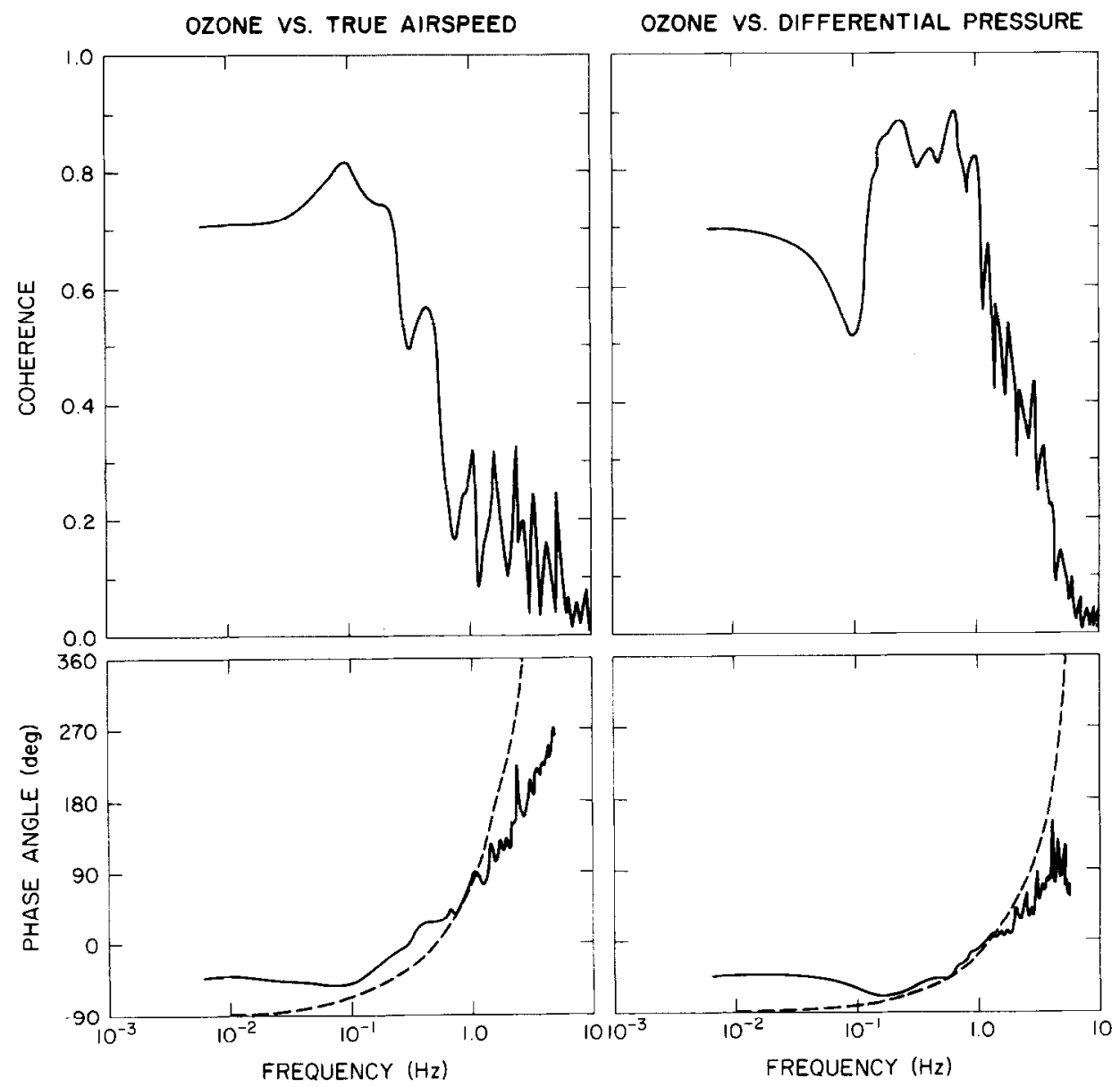

Fig. 1. Coherence and phase angle between ozone and aircraft true airspeed, and between ozone and differential pressure measured across the ozone sensor intake nozzle. The dashed lines are phase angles for time delays of $0.5 \mathrm{~s}$ (left) and $0.2 \mathrm{~s}$ (right).

Figure 1 shows that on 28 April the phase angles between uncorrected ozone and both airspeed and pressure difference do not go to zero at low frequencies, but rather the airspeed and pressure differences lag the ozone values by about $45^{\circ}$. After removing the pressure and flow rate sensitivities of the ozone output by use of 
Equation (1), a significant correlation remained between the time derivative of pressure difference and ozone. In fact, between 0.1 and $1.0 \mathrm{~Hz}$ the contribution of the derivative is larger than the contribution from the pressure signal itself. Therefore, the time delays were obtained by a linear fit to the phase angle between ozone and the derivatives of the pressure difference and airspeed.

The results of this analysis give a time delay of $0.5 \mathrm{~s}$ for the entire measurement system, based on the phase angle between ozone and airspeed. A time delay of $0.2 \mathrm{~s}$ was found for the sensor itself based on the phase angle between ozone and differential pressure. This delay is due to a combination of an actual time lag and instrumental time response. The time constant of the instrument itself was estimated to be $<0.1 \mathrm{~s}$. (If the instrument did have a time constant of $0.1 \mathrm{~s}$, the instrument output would be about $92 \%$ of the unattenuated signal at $0.7 \mathrm{~Hz}$.) The difference between these time delays, $0.3 \mathrm{~s}$, can be ascribed to the ducting and separation of the ozone sensor from the airspeed sensor. At an airspeed of $70 \mathrm{~m} \mathrm{~s}^{-1}$, the $5.9 \mathrm{~m}$ separation is equivalent to a delay of about $0.084 \mathrm{~s}$. The remaining time delay can be ascribed approximately equally to the flow time through the manifold and the flow time through the tubing connecting the manifold and sensor. Corrections for these time delays were made in the ozone data before calculation of turbulent ozone fluxes.

We can estimate the effect of an error in time delay on the flux of ozone from the cospectral plots in Figure 5. This figure shows that contributions to the fluxes of ozone and temperature are negligible above about $60 \mathrm{rad} \mathrm{km}^{-1}$, which is about $0.7 \mathrm{~Hz}$. A phase shift of $>25^{\circ}$ at this frequency will begin to have a noticeable effect on the fluxes. This is equivalent to a time lag of $\sim 0.1 \mathrm{~s}$, which is also about the accuracy with which the time lag could be determined. Thus, flux measurements at $150 \mathrm{~m}$ height are not significantly affected by the errors in estimating the time lag and time constant of the ozone measurement. At $15 \mathrm{~m}$ height, however, the cospectral peak of temperature and vertical velocity shifts to about $400 \mathrm{~m}$, and about $14 \%$ of the flux is at frequencies $>1 \mathrm{~Hz}$. Therefore, ozone flux at $15 \mathrm{~m}$ may be underestimated by 10 to $20 \%$; at $75 \mathrm{~m}$ by 5 to $10 \%$.

The contribution of the time derivative of the pressure difference to the measured ozone values was removed by filtering the derivative of pressure difference with a $1 \mathrm{~Hz}$ low-pass filter (since the coherence between ozone and pressure is small for frequencies greater than $1 \mathrm{~Hz}$ ), plotting the ozone output versus the time derivative of differential pressure, fitting a straight line to the resulting set of points, multiplying the differential pressure by the slope of the line, and subtracting this from the ozone output. The magnitude of this correction is $4.6 \mathrm{~d} \Delta P / \mathrm{d} t$, with $\Delta P$ in torr and ozone in parts per billion by volume.

\section{Observations}

The ozone sensor was used on two flights in the daytime convective boundary layer during an experiment involving the Boulder Atmospheric Observatory (BAO) instrumented tower (Kaimal, 1978). An ethylene chemiluminescence ozone monitor 
(McMillan Electronics Corporation Series 1100) was mounted on the instrument elevator of the tower to measure ozone concentrations at various elevations. This instrument was calibrated with the NCAR Atmospheric Quality Division (AQD) Dasibi ultraviolet photoabsorption monitor. A primary objective of this experiment was to evaluate the extent to which the tower measurements are representative of the surrounding area, which consists of gently rolling terrain used for grazing, dryland and irrigated farming, and surburban living. An X-shaped flight track designed to accomplish this is shown in Figure 2. This track, which extends $16 \mathrm{~km}$ out from the

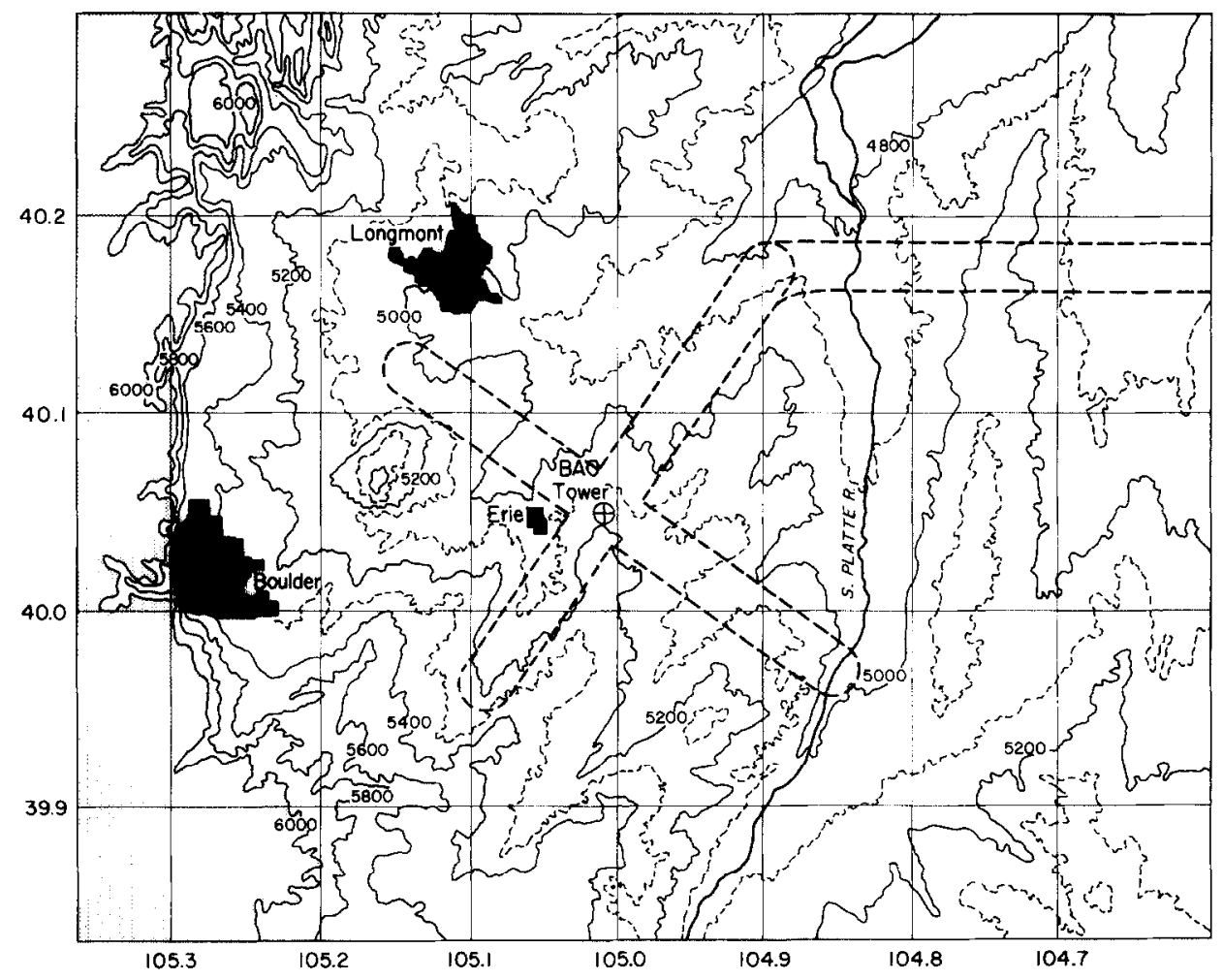

Fig. 2. Contour map of the area surrounding the Boulder Atmospheric Observatory tower. Contour interval is 200 feet $(60 \mathrm{~m})$ with dashed lines at intermediate 100 foot intervals. Contours above 6000 feet $(1800 \mathrm{~m})$ in the mountains to the west are not shown. The airplane flight track for hoth 26 and 28 April is also shown.

tower at the center, was flown repeatedly at $150 \mathrm{~m}$ above the ground to obtain sufficient statistics for making meaningful comparisons with time-averaged tower measurements. In addition, during the two flights with the ozone sensor, two additional flight legs, one at $75 \mathrm{~m}$ and the other at $15 \mathrm{~m}$ above the ground, were flown east of the northeast corner of the $\mathrm{X}$. This area is relatively sparsely populated range land. Near the tower, flight levels below $150 \mathrm{~m}$ were not possible because of the suburban surroundings. 
The first flight was between 1518 and 1653 MST on 26 April 1978 and the second from 0820 to 1041 MST on 28 April 1978. The sky was clear during the first flight and the winds were northerly from 2 to $6 \mathrm{~m} \mathrm{~s}^{-1}$. Thus, the area was not directly downwind of a major nearby source of air pollution. The sky was also clear at the beginning of the second flight, but was soon covered by a high overcast. Winds were westerly from 5 to $15 \mathrm{~m} \mathrm{~s}^{-1}$, so that the tower was approximately downwind of Boulder (21 km distant).

\section{Results}

Since most of the data were obtained at $150 \mathrm{~m}$ height, we first discuss in detail the spectra, cospectra and turbulence statistics for the flight legs at this level. As a first step, the flight legs are split into $204.8 \mathrm{~s}$ (or about $14 \mathrm{~km}$ ) segments. The mean and a least-square linear trend are then removed from the segments. The mean ozone

TABLE I

Turbulence statistics and surface-Iayer transfer parameters for airplane flight legs over eastern Colorado

\begin{tabular}{lll}
\hline & 26 April 78 & 28 April 78 \\
& 1531 to $1617 \mathrm{MST}$ & 0840 to $1009 \mathrm{MST}$ \\
& (a) $150 \mathrm{~m}$ height above & \\
& the ground & \\
\hline Number of segments & 5 & 17 \\
\hline $\bar{s}(\mathrm{ppb})$ & $113 \pm 5$ & $46 \pm 1$ \\
$\sigma_{s}(\mathrm{ppb})$ & $5.1 \pm 1.0$ & $4.6 \pm 0.7$ \\
$\sigma_{w}\left(\mathrm{~m} \mathrm{~s}^{-1}\right)$ & $0.92 \pm 0.10$ & $1.29 \pm 0.10$ \\
$\sigma_{T}\left(\mathrm{~K}^{\prime}\right.$ & $0.26 \pm 0.04$ & $0.23 \pm 0.03$ \\
$w^{\prime} s^{\prime}\left(\mathrm{m} \mathrm{s}^{-1} \mathrm{ppb}\right)$ & $-0.34 \pm 0.39$ & $-0.65 \pm 0.32$ \\
\hline$w^{\prime} T^{\prime}\left(\mathrm{m} \mathrm{s}^{-1} \mathrm{~K}\right)$ & $0.075 \pm 0.018$ & $0.156 \pm 0.042$ \\
$\left.\overline{\left(u^{\prime} w^{\prime 2}\right.} \overline{v^{\prime} w^{\prime 2}}\right)^{1 / 4}\left(\mathrm{~m} \mathrm{~s}^{-1}\right)$ & $0.38 \pm 0.19$ & $0.63 \pm 0.19$ \\
$r_{w s}$ & -0.072 & -0.11 \\
$r_{w t}$ & 0.32 & 0.53 \\
\hline
\end{tabular}

(b) Average of $15 \mathrm{~m}$ and $75 \mathrm{~m}$ levels

(two segments at each level on each day)

\begin{tabular}{lcc}
\hline $\bar{s}(\mathrm{ppb})$ & 87 & 50 \\
$\sigma_{s}(\mathrm{ppb})$ & 7.6 & 3.7 \\
$\sigma_{w}\left(\mathrm{~m} \mathrm{~s}^{-1}\right)$ & 0.77 & 0.83 \\
$\sigma_{T}(\mathrm{~K})$ & 0.30 & 0.38 \\
$w^{\prime} s^{\prime}\left(\mathrm{m} \mathrm{s}^{-1} \mathrm{ppb}\right)$ & -0.106 & -0.067 \\
$w^{\prime} T^{\prime}\left(\mathrm{m} \mathrm{s}^{-1} \mathrm{~K}\right)$ & 0.093 & 0.134 \\
$u_{*}\left(\mathrm{~m} \mathrm{~s}^{-1}\right)$ & 0.35 & 0.35 \\
$C_{s} \times 10^{3}$ & 0.20 & 0.25 \\
$C_{D} \times 10^{3}$ & 4.1 & 3.7 \\
$r_{w s}$ & -0.018 & -0.022 \\
$r_{w T}$ & 0.40 & 0.42 \\
$v_{d}\left(\mathrm{~cm} \mathrm{~s}^{-1}\right)$ & 0.12 & 0.13 \\
\hline
\end{tabular}


concentration, $\overline{\mathrm{s}}$, (the overbar indicates an average over the $14 \mathrm{~km}$ segment) measured by the aircraft in the vicinity of the tower at $150 \mathrm{~m}$ was adjusted to agree with the value measured at the $150 \mathrm{~m}$ level on the tower during the 26 April flight. Tower ozone measurements were not made on 28 April. Table I shows that the mean ozone concentration at $150 \mathrm{~m}$ is much greater during the 26 April afternoon flight than during the 28 April morning flight. A relatively high afternoon value is observed frequently and results from entrainment of overlying air of greater mean ozone concentration, possibly of stratospheric origin (Danielsen et al., 1976), and perhaps some generation of ozone through photochemical reactions. Similarly, the small value on the morning of 28 April is probably a result of the destruction of ozone at the surface through the night without replacement by buoyancy-driven entrainment or photochemical reactions.

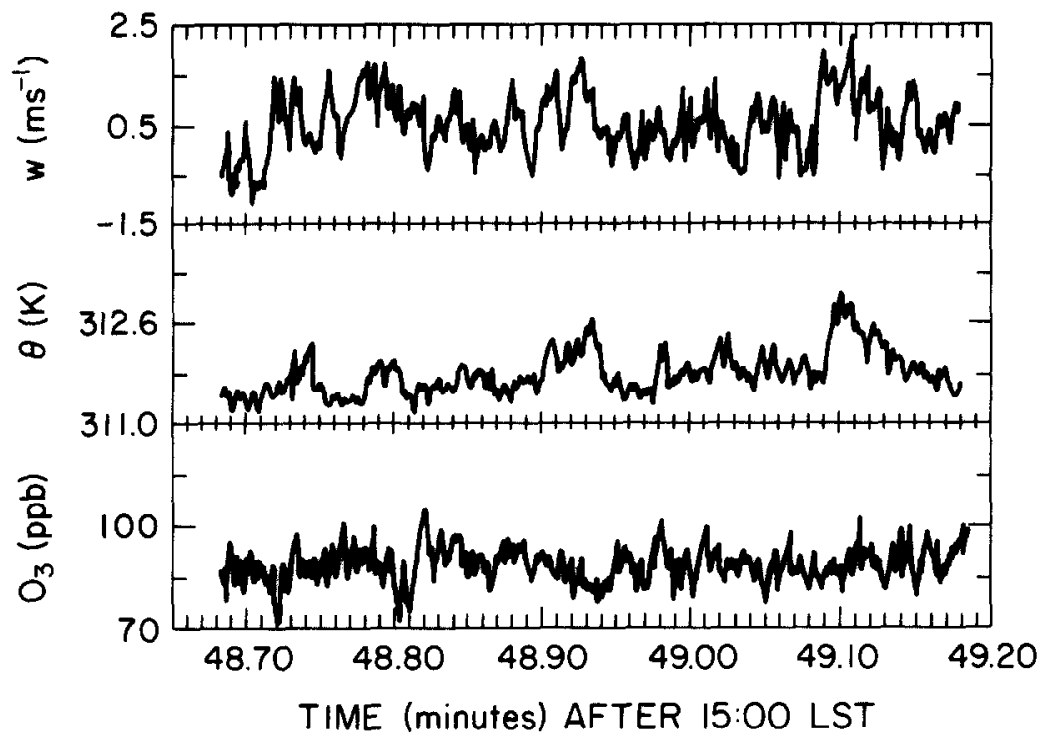

Fig. 3. Time series of vertical velocity, potential temperature and ozone for a $30 \mathrm{~s} \mathrm{segment}$ at $15 \mathrm{~m}$ height above the ground on 26 April 1978.

Examination of the ozone time series (Figure 3), as well as comparison of the spectral density of ozone fluctuations with vertical velocity, $w$, and temperature, $T$, (Figure 4) indicate that the ozone measurement has more variation at higher frequencies than either $w$ or $T$. Both the spectra and cospectra of $w$ and $T$, and the cospectra of $w$ and $s$ (Figure 5) have a peak between 600 and $2000 \mathrm{~m}$ wavelength with a valley in between at about $1000 \mathrm{~m}$ wavelength. Spectra of $w$ and $T$ have the expected slope of $-5 / 3$ at wavelengths shorter than about $200 \mathrm{~m}$. The peak in the ozone spectrum, however, is at about $100 \mathrm{~m}$. At this point, we do not know whether the ozone spectra are actually significantly different from the temperature and vertical velocity spectra, possibly because of internal sources and sinks of ozone 


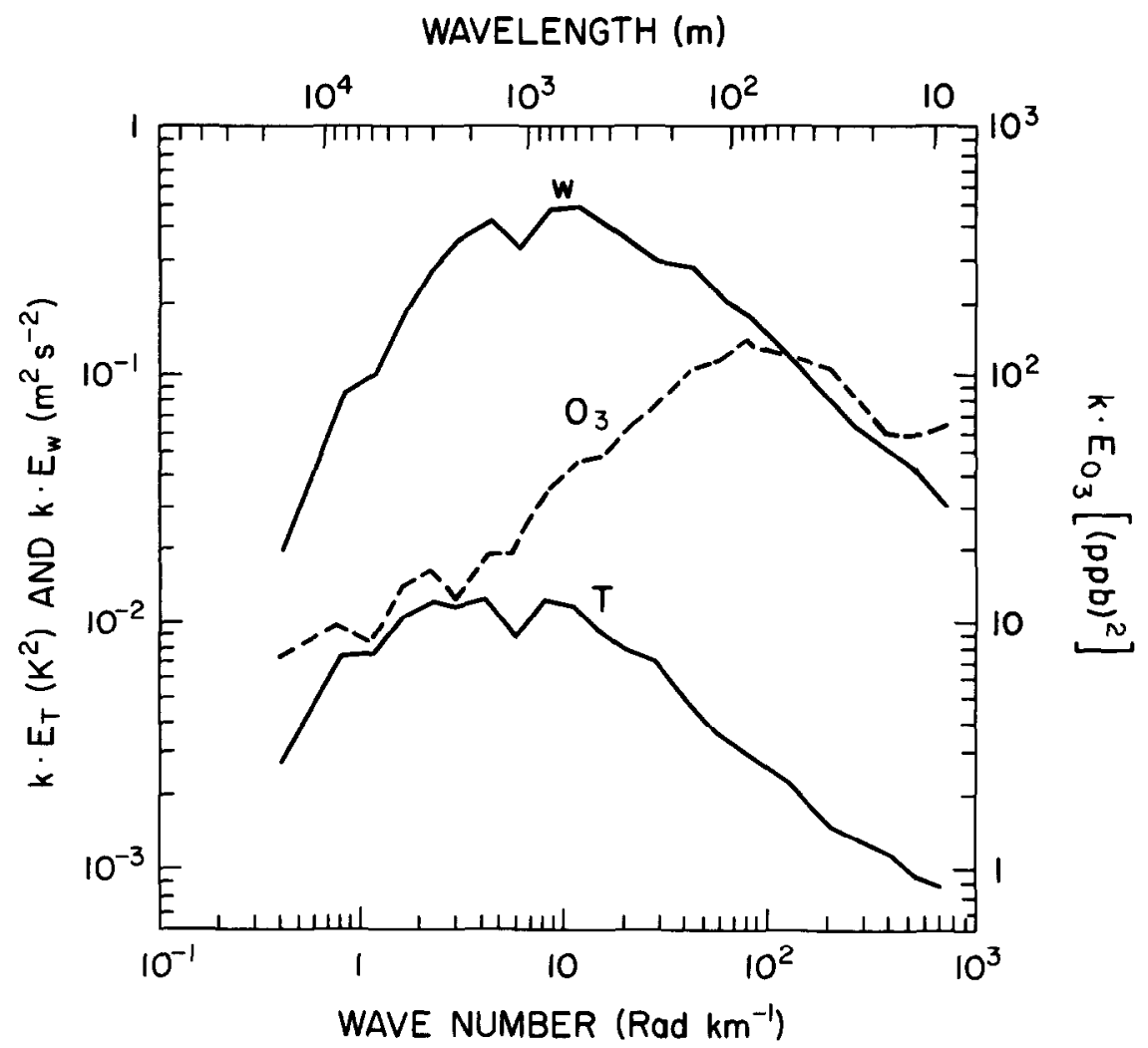

Fig. 4. Averaged spectra of vertical velocity, temperature and ozone multiplied by wave number, $k$, from all the flight segments at $150 \mathrm{~m}$ on 28 April 1978.

within the boundary layer (e.g., photochemical reactions), or whether the differences are mainly the result of instrumental noise. In the subsequent discussion, however, we present evidence that there is instrumental noise in the measured ozone fluctuations. There is no indication, however, that the noise is correlated with vertical velocity; rather, it appears to be due to inherent noise in the instrumentation. Therefore, the ozone flux measurements should be unaffected.

Measurements of the vertical flux of ozone, $\overline{w^{\prime} s^{\prime}}$, (the prime indicates an instantaneous departure from the least-square linear trend calculated for each variable over the $14 \mathrm{~km}$ segment) at $150 \mathrm{~m}$ are presented in Table $\mathrm{I}$. We can obtain a relationship between the correlation coefficient, $r_{w s} \equiv \overline{w^{\prime} s^{\prime}} /\left(\sigma_{w} \sigma_{s}\right)$, where $\sigma_{w}$ and $\sigma_{s}$ are the standard deviations of $w$ and $s$ over the $14 \mathrm{~km}$ segments, and the statistical significance of the flux measurements by using the approach suggested by Wyngaard (1974). He shows that if $\overline{\left(w^{\prime} s^{\prime}\right)^{2}}$ is quasi-normal (i.e., that $\overline{\left(w^{\prime} s^{\prime}\right)^{2}} \approx \sigma_{w}^{2} \sigma_{s}^{2}+2 \overline{\left(w^{\prime} s^{\prime}\right)^{2}}$, the ratio of the variance of a set of flux measurements to the mean value of the flux measurements squared is

$$
\sigma_{w s}^{2} /{\overline{\left(w^{\prime} s^{\prime}\right)^{2}}}_{2}^{2\left(1+r_{w s}^{2}\right)} \frac{l}{r_{w s}^{2}} \frac{l}{L}
$$




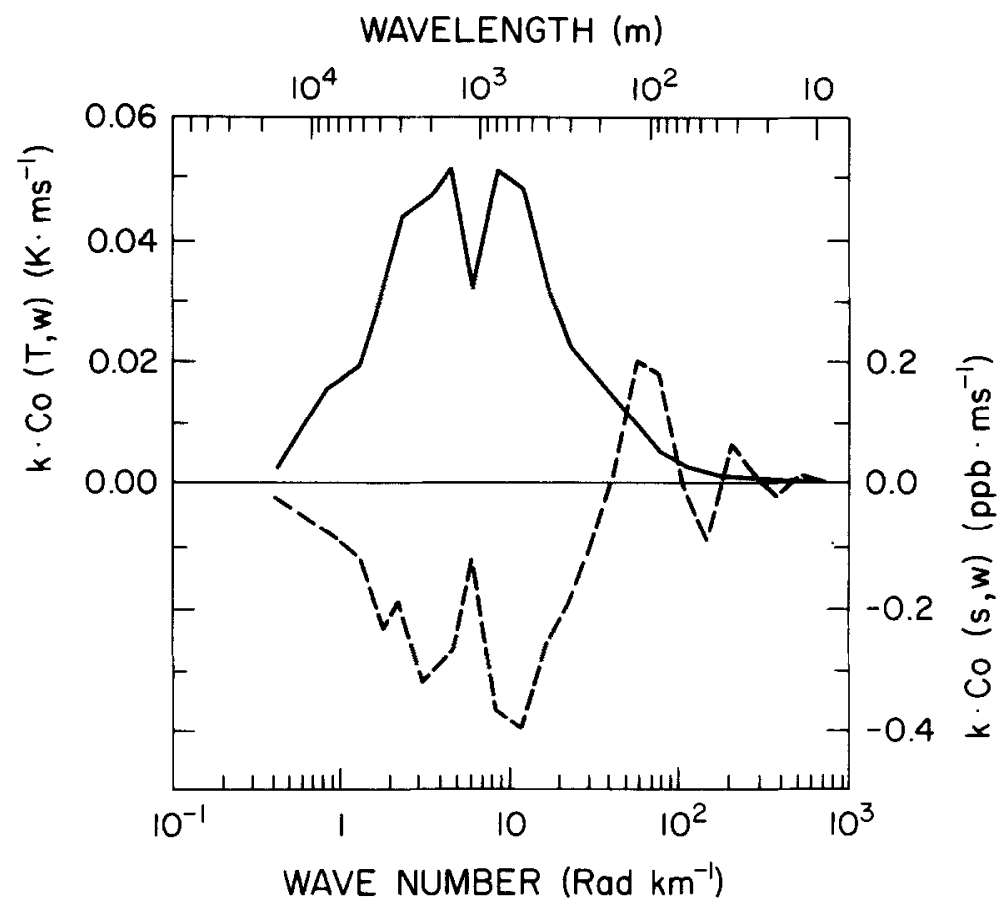

Fig. 5. Averaged cospectra of temperature and vertical velocity (solid line), and ozone and vertical velocity (dashed line) multiplied by wave number, $k$, from all the flight segments at $150 \mathrm{~m}$ on 28 April 1978. The vertical fluxes of temperature and ozone are equal to the areas under the curves.

where $l$ is the integral scale of the transport process and $L$ is the averaging length of each estimate of $\overline{w^{\prime} s^{\prime}}$. Wyngaard (1974) also presents data showing that the quasi-Gaussian approximation is valid for $\overline{\left(w^{\prime} T^{\prime}\right)^{2}}$ in the surface layer. Solving Equation (2) for $l$, and putting in values from Table $I$ for the temperature flux and correlation coefficient at $150 \mathrm{~m}$ for 28 April, we get $l \approx 100 \mathrm{~m}$. For ozone, however, $l \approx 20 \mathrm{~m}$.

Figure 5 shows that the cospectra of $w$ and $T$, and of $w$ and $s$ are very similar except for wavelengths $<200 \mathrm{~m}$. Furthermore, Lumley and Panofsky (1964) show that a cospectral peak at $\sim 600 \mathrm{~m}$ is consistent with an integral scale of $\sim 100 \mathrm{~m}$. Therefore, it is likely that a good part of the difference between the integral scales of the transport processes is due to noise in the ozone output which increases the measured values of $\sigma_{s}$ and thus decreases $r_{w s}$. If we assume that the integral scale for ozone transport is the same as for temperature, we find from Equation (2) that the measured value of $\sigma_{s}$ is about 2.3 times the value required to give identical integral scales. Thus, the actual value of $r_{w s}$ on 28 April may be closer to -0.25 .

Ozone flux measurements at $150 \mathrm{~m}$ are negative on both days, although with considerable scatter. Using the Student $t$-distribution at the $5 \%$ level, the standard deviations of the statistics presented in Table I for 26 April $(n=5)$ should be multiplied by 1.24 , and for 28 April $(n=17)$ by 0.51 . Thus, with a $95 \%$ probability, 
the average flux estimate for 26 April lies between -0.82 and $+0.14(\mathrm{ppb}) \mathrm{m} \mathrm{s}^{-1}$, while on 28 April, the limits are -0.81 and -0.48 (ppb) $\mathrm{m} \mathrm{s}^{-1}$.

These results indicate a fundamental problem in measuring fluxes of atmospheric constituents, viz., that in many cases the variability of the flux estimates may be high, mainly because of a small correlation coefficient between vertical velocity and the constituent. In such cases, a long averaging time may be required in order to obtain a stable flux estimate. For 26 April, we see that $72 \mathrm{~km}$ (i.e., $1024 \mathrm{~s}$ of flight time) is not a sufficient averaging length to determine with a reasonably high probability even the sign of the flux. On the other hand, on 28 April a distance of $244 \mathrm{~km}$ is sufficient to determine the flux to within an accuracy of about $26 \%$ with $95 \%$ probability. To some extent, these may be conservative estimates, since this assumes that the scatter in the flux estimates is random i.e., that the ozone flux is horizontally homogeneous and steady-state. Although terrain variations and ground cover do not change drastically from one region to another, some variability does exist, which could make a systematic contribution to the standard deviations of the turbulence statistics.

We can examine the behaviour of the standard deviation of ozone concentration by comparing it to free convection predictions. Figure 6 shows values of standard deviations of vertical velocity $\left(\sigma_{w}\right)$, temperature $\left(\sigma_{T}\right)$ and ozone $\left(\sigma_{s}\right)$, normalized by

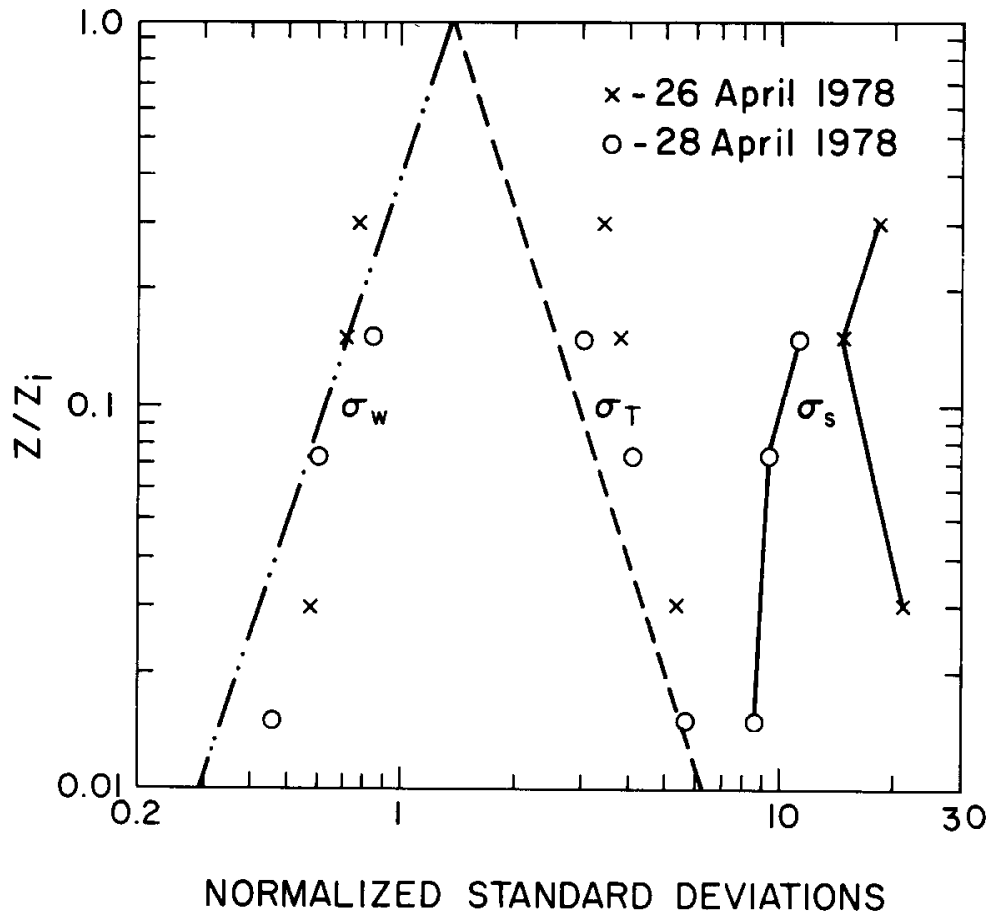

Fig. 6. Standard deviations of vertical velocity, temperature and ozone normalized by mixed layer scaling parameters. Dashed lines are free convection predictions of Kaimal et al. (1978) for the standard deviations of vertical velocity and temperature. 
the mixed-layer scaling parameters

$$
\begin{aligned}
& w_{*}=\left[\frac{g}{\bar{T}}\left(\overline{w^{\prime} T^{\prime}}\right)_{0} z_{i}\right]^{1 / 3} \\
& \theta_{*}=\left(\overline{w^{\prime} T^{\prime}}\right)_{0} / w_{*} \\
& s_{*}=-\left(\overline{w^{\prime} s^{\prime}}\right)_{0} / w_{*}
\end{aligned}
$$

where $g / \bar{T}$ is the buoyancy parameter (gravitational acceleration divided by the mean air temperature), $z_{i}$ is the height of the boundary layer, and the zero subscript refers to surface layer values. The lines in this figure use the empirically determined coefficients reported by Kaimal et al. (1976) for the free convection layer power law predictions for $\sigma_{w}$ and $\sigma_{T}$. Lenschow et al. (1980) have found that the standard deviation of humidity, which is very nearly a passive scalar, agrees with the formulation for temperature,

$$
\sigma_{T} / \theta_{*}=1.3\left(z / z_{i}\right)^{-1 / 3}
$$

where $z$ is height above the surface. Therefore, we would expect that, in the absence of internal sources or sinks of ozone variance, or significant contributions from entrainment through the top of the mixed layer or from horizontal advection, the ozone variance should lie close to that for temperature. Instead, we find that ozone variance is considerably larger than temperature variance, particularly at the higher levels. Although this is probably due mainly to noise, other factors may also increase the ozone variance.

Free convection scaling assumes that ozone flux is constant with height and that the surface ozone flux is the only relevant scaling variable that involves ozone, i.e., the destruction of ozone at the earth's surface is assumed to be the source of ozone variance aloft. For the cases considered here, however, the flux at $150 \mathrm{~m}$ was considerably larger than near the surface (Table I), which may contribute to departures of the ozone variance from the free convection prediction. In the upper part of the boundary layer (usually for $z / z_{i}>0.5$ ), entrainment of warm, dry air from above the convective boundary layer results in temperature and humidity variances larger than predicted by Equation (3) (Lenschow et al. 1980). Ozone variance may also be similarly generated by this process. In addition, however, internal sources or sinks of ozone in the atmosphere may also generate fluctuations. With the assumption of horizontal homogeneity, the budget equation for the variance of ozone is

$$
\frac{1}{2} \frac{\partial \overline{s^{\prime 2}}}{\partial t}=-\overline{w^{\prime} s^{\prime}} \frac{\partial \bar{s}}{\partial z}-\frac{1}{2} \frac{\partial \overline{w^{\prime} s^{\prime 2}}}{\partial z}-\varepsilon_{s}+\overline{Q^{\prime} s^{\prime}}
$$

where $\varepsilon_{s}$ is the rate at which the molecular diffusivity of ozone dissipates ozone fluctuations and $Q$ is the sum of the internal sources and sinks of ozone, i.e., the rate of production or dissipation of ozone within a parcel of air. We can estimate the magnitude of the source term in Equation (4), $-\overline{w^{\prime} s^{\prime}} \partial \bar{s} / \partial z$, by analogy with the 
temperature variance equation in the free convection layer (Wyngaard et al., 1978),

$$
-\overline{w^{\prime} s^{\prime}} \frac{\partial \bar{s}}{\partial z}=0.93 \frac{w_{*} s_{*}^{2}}{z}\left(z / z_{i}\right)^{-1 / 3} \text {. }
$$

They show that the transport term in the surface layer is considerably smaller than the production term. Thus, if there were no other source of ozone variance, production by the gradient term must be approximately equal to the dissipation. In this way we can estimate how large the internal source term, $\overline{Q^{\prime} s^{\prime}}$, must be in order to alter the balance of the variance budget equation significantly, and thus result in departures of the variance from the form predicted by Equation (3). For 28 April, at $150 \mathrm{~m}$, the value of Equation (5) is $\sim 0.3 \times 10^{-4}(\mathrm{ppb})^{2} \mathrm{~s}^{-1}$. Since $\overline{Q^{\prime} s^{\prime}} \leqslant \sigma_{Q} \sigma_{s}$, $\sigma_{Q}>0.5 \times 10^{-3}(\mathrm{ppb}) \mathrm{s}^{-1}$. For this case, therefore, the standard deviation of the internal production of ozone within the boundary layer must be at least of order $10^{-4}(\mathrm{ppb}) \mathrm{s}^{-1}$ before it is likely to have a significant effect on the variance equation.

At this point, we do not have any knowledge of how large this term is likely to be in the atmosphere. The chemistry of tropospheric ozone is such that large fluctuations can only be produced in the presence of sources of nitric oxide. The only important nitric oxide sources are combustion processes (wild fires, industry, utility or transport) and lightning. (An alternate technique to test the response and time delay of aircraft ozone sensors may be to fly through a combustion plume purposely since the ozone decrease should be well correlated with the increased temperature and upward moving air.)

In the absence of nitric oxide sources, there can be relatively slow photochemical generation of ozone by a photochemical smog mechanism. If polluted air has not had time to mix well with surrounding less polluted air, this could also be a significant source of ozone variance, since the rate at which ozone can be generated by this process can be as much as $10^{2}$ (ppb) s ${ }^{1}$ in very polluted air. Van Dop et al (1977) have found evidence for mean photochemical production of ozone in a rural environment over The Netherlands on the basis of several observations of an ozone concentration maximum at mid-level in a convective boundary layer. In either old polluted or clean air, however, the only major sources of ozone variance should be either the ground-level sink or downward mixing of air from above the boundary layer with different ozone concentrations.

We can estimate the extent to which the mean ozone concentration is balanced in the boundary layer between the $150 \mathrm{~m}$ and the 75 and $15 \mathrm{~m}$ flight levels, although r. ot with much statistical significance. The budget equation for mean ozone concelltration over a particular area is

$$
\frac{\partial \bar{s}}{\partial t}=-\frac{\partial \overline{w^{\prime} s^{\prime}}}{\partial z}-\bar{u} \frac{\partial \bar{s}}{\partial x}+Q,
$$

where $x$ is the coordinate along the direction of the mean wind, $\bar{u}$. On 26 April, data from the BAO tower can be used to estimate the time rate of change of ozone. From Figure 7, we estimate it to be about $2.4 \times 10^{-3}(\mathrm{ppb}) \mathrm{s}^{-1}$. 


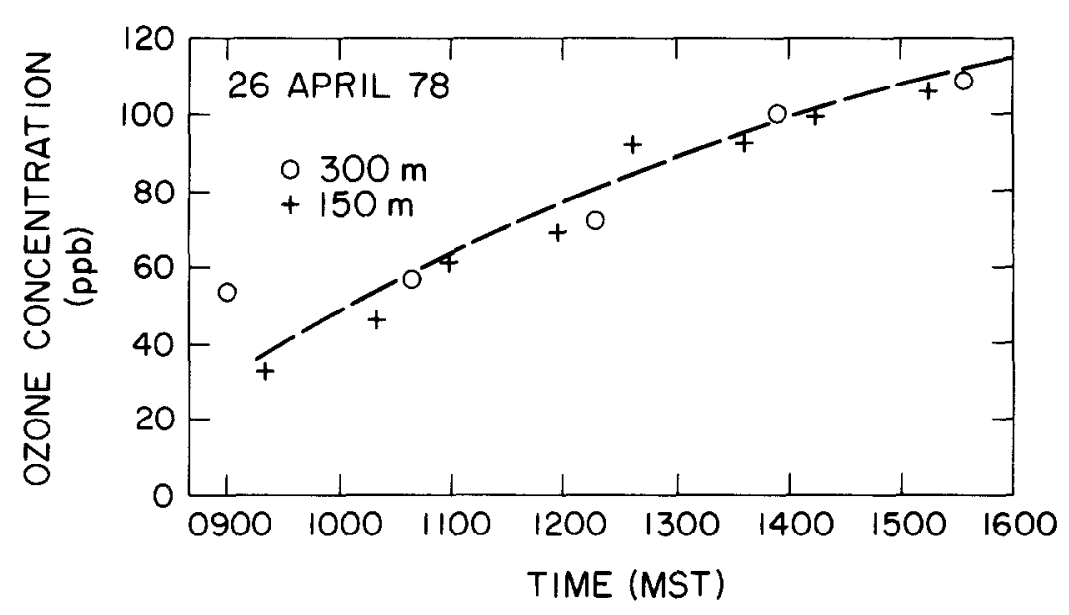

Fig. 7. Ozone mixing ratio measurements from the BAO tower.

The averaged measured fluxes at 75 and $15 \mathrm{~m}$, averaged together for each of the flights, (which amounts to four segments for each day) are -0.11 and $-0.07(\mathrm{ppb}) \mathrm{m} \mathrm{s}^{-1}$, respectively, for 26 and 28 April. Combining the two days, we have $-0.09 \pm 0.12(\mathrm{ppb}) \mathrm{m} \mathrm{s}^{-1}$ at an average height of $45 \mathrm{~m}$. This is well within the surface layer, where we would expect that the flux can be considered equal to the surface value. The flux at $150 \mathrm{~m}$ averaged together for both days is $-0.49(\mathrm{ppb}) \mathrm{m} \mathrm{s}^{-1}$. Thus, the flux divergence term is $-\partial \overline{w^{\prime} s^{\prime}} / \partial z=$ $3.9 \times 10^{-3}(\mathrm{ppb}) \mathrm{s}^{-1}$.

The horizontal advection term, $-\bar{u} \partial \bar{s} / \partial x$, can also be obtained from the aircraft measurements. On 26 April, however, the horizontal gradient of ozone could not be estimated because of the large scatter in the gradient measurements. On 28 April, $-\bar{u} \partial \bar{s} / \partial x=-1.3 \times 10^{-3}(\mathrm{ppb}) \mathrm{s}^{-1}$.

Thus, qualitatively the budget is in reasonable balance, considering the measurement limitations and statistical scatter. The measurements are not sufficiently accurate, in this case, to estimate the source term, $Q$. We note, however, that in principle all the terms in Equation (6), except for $Q$, can be estimated in a carefully designed aircraft experiment. Therefore, in some situations it may be possible to estimate $Q$ as the residual in Equation (6).

An interesting feature of this budget is the relatively large magnitude of the flux divergence term as compared to the flux at the surface divided by the boundary layer height, $z_{i}$. We do not have sufficient data at this point to indicate whether this is a common occurrence. We also note from Table I that the flux divergence is higher during the $28 \wedge$ pril morning flight, which agrees with the observation that the mean ozone concentration usually increases more rapidly in the morning than in the afternoon. For this case, however, the layer of nearly constant flux near the surface, which is a usual definition of the surface layer, is very thin; $150 \mathrm{~m}$ is already too high. Therefore, we use the fluxes measured at 15 and $75 \mathrm{~m}$ to estimate the surface-layer 
fluxes in the following discussion with the caution that the ozone flux estimates are not very significant because of the relatively short measurement period and possibly some reduction of the flux estimates due to instrumental response. (Although $15 \mathrm{~m}$ is more definitely in the surface layer, we include also fluxes at $75 \mathrm{~m}$ to improve the significance of the estimates.)

The aerodynamic transfer coefficients for momentum and ozone are defined by

$$
\begin{aligned}
& \left.C_{D}=\left[\overline{\left(w^{\prime} u^{\prime}\right.}\right)_{0}^{2}+\left(\overline{w^{\prime} v^{\prime}}\right)_{0}^{2}\right]^{1 / 2} / \bar{u}^{2}=u_{*}^{2} / \bar{u}^{2} \\
& C_{s}=-\left(\overline{w^{\prime} s^{\prime}}\right)_{0} / \bar{u} \bar{s}
\end{aligned}
$$

where $\bar{u}$ and $\bar{v}$ are the alongwind and crosswind components at a reference height (in our case, the average of the values at 15 and $75 \mathrm{~m}$ ), and $u_{*}$ is the surface friction velocity. We have assumed that the mean ozone concentration at the surface is zero. The values in Table $I$ reflect the relatively greater efficiency of the momentum transport process compared to ozone transport.

The deposition velocity, defined by

$$
v_{d}=-\frac{\overline{w^{\prime} s^{\prime}}}{\bar{s}}=C_{s} \bar{u}
$$

has a value of $\sim 0.13 \mathrm{~cm} \mathrm{~s}^{-1}$ for the two days (Table I). Previous estimates of the deposition velocity over land have varied from 0.1 to $2 \mathrm{~cm} \mathrm{~s}^{-1}$ (McMahon and Denison, 1979). Such a large variation is not surprising in view of the variable resistance of vegetation to ozone removal depending on whether the stomata are open or closed (Turner et al., 1974), and a likely dependency of the removal rate on the mean wind, surface roughness and surface-layer stratification. Furthermore, most previous estimates are based on indirect methods of estimating ozone flux. Wesely et al. (1978), who also used the direct eddy correlation method of flux measurement, report values of $v_{d}$ from 0.2 to $0.8 \mathrm{~cm} \mathrm{~s}^{-1}$ above a senescent maize canopy. We would expect values over eastern Colorado to be low compared to this because of the sparseness of the vegetation.

\section{Conclusions}

An aircraft instrumented for high-frequency air motion measurements can bo a useful platform for measuring turbulent fluxes of atmospheric constituents providid fast-response sensors can be developed for instantaneous measurements of the constituents. A preliminary instrument has been developed for ozone. Here we have demonstrated its use in an aircraft for measurements of turbulent ozone flux in a convective boundary layer. For the most part, the mcasurements are consistent with previous estimates. We have also shown that long averaging lengths may be required in order to obtain statistically significant estimates of the fluxes since the sources and sinks of ozone may not be effective enough to develop a significant correlation between the constituent and vertical velocity. Even ozone, which is readily destroyed 
at the surface, may require a hundred or more kilometers of averaging distance to obtain a stable flux estimate.

The next step is to improve this measurement capability for a more detailed study of ozone structure and turbulence statistics. The techniques described here can be useful for studying the ozone budget in the boundary layer, including (1) evolution of possible internal sources and sinks of ozone, (2) the destruction of ozone at the earth's surface, (3) entrainment of ozone through the top of the mixed layer, and (4) horizontal advection. In addition, the turbulence statistics are useful, in themselves, to study the behavior of a scalar in the boundary layer that has a source at the top and a sink at the surface.

\section{Acknowledgments}

We wish to acknowledge the cooperation and support of the NCAR Research Aviation Facility and the NOAA Wave Propagation Laboratory BAO Tower personnel during the field phase of the BAO Site Evaluation Study. We are grateful to J. Wyngaard for pointing out to us the relationship between the correlation coefficient, the integral scale and the standard deviation of flux measurements.

\section{References}

Danielsen, E., Bleck, R., Shedlovsky, J. Wartburg, A., Haagenson, P., and Pollock, W.: 1976, 'Observed Distribution of Radioactivity, Ozone, and Potential Vorticity Associated with Tropopause Folding', $J$. Geophys. Res. 75, 2353-2361.

Eastman, J. A. and Stedman, D. H.: 1977, 'A Fast Response Sensor for Eddy-Correlation Flux Measurements', Atmos. Envir. 11, 1209-1211.

Kaimal, J. C.: 1978, 'NOAA Instrumentation at the Boulder Atmospheric Observatory', Preprint Volume, Fourth Symposium on Meteorological Observations and Instrumentation, April 10-14, 1978, Denver, CO. Published by the American Meteorological Society, Boston, MA, 35-40.

Kaimal, J. C. Wyngaard, J. C., Haugen, D. A., Coté, Izumi, Y., Caughey, S. J., and Readings, C. J.: 1976, 'Turbulence Structure in the Convective Boundary Layer', J. Atmos. Sci. 33, 2152-2169.

Lenschow, D. H., Cullian, C. A., Friesen, R. B., and Brown, E. N.: 1978, 'The Status of Air Motion Measurements on NCAR Aircraft', Preprint Volume, Fourth Symposium on Meteorological Observations and Instrumentation, April 10-14, 1978, Denver, CO. Published by the American Meteorological Society, Boston, MA, 433-438.

Lenschow, D. H., Wyngaard, J. C., and Pennell, W. T.: 1980, 'Mean-Field and Second-Moment Budgets in a Baroclinic, Convective Boundary Layer', to appear in J. Atmos. Sci.

Lumley, J. L and Panofsky, H. A.: 1964, The Structure of Atmospheric Turbulence. John Wiley and Sons, Inc., New York, 239.

McFarland, M., Kley, D., Drummon, J. W., Schmeltekopf, A. L., and Winkler, R. H.: 1979, 'Nitric Oxide Measurements in the Equatorial Pacific Region', Geophys. Res. Letts. 6, 605-608.

McMahon, T. A. and Denison, P. J.: 1977, 'Empirical Atmospheric Deposition Parameters - A Survey', Almos. Envir. 13, 571-585.

Stedman, D. H., Daby, E. E., Stuhl, F., and Niki, H.: 1972, 'Analysis of Ozone and Nitric Oxide by a Chemiluminescence Method in Laboratory and Atmospheric Studies of Photochemical Smog', J. Air. Poll. Control Assoc. 22, 26-264.

Turner, N. C., Waggoner, P. E. and Rich, S.: 1974, 'Removal of Ozone from the Atmosphere by Soil and Vegetation', Nature 250, 486-488. 
Von Dop, H., Guicherit, R., and Lanting, R. W.: 1977, 'Some Measurements of the Vertical Distribution of Ozone in the Atmospheric Boundary Layer', Atmos. Envir. 11, 65-71.

Wesley, M. L., Eastman, J. A., Cook, D. R., and Hicks, B. B.: 1978, 'Daytime Variations of Ozone Eddy Fluxes to Maize', Boundary-Layer Meteorol. 15, 361-373.

Wyngaard, J. C.: 1974, 'On Surface-Layer Turbulence', Workshop on Micrometeorology, D. A. Haugen, Editor, American Meteorological Society, 45 Beacon St., Boston, MA 02108, 101-149.

Wyngaard, J. C., Pennell, W. T., Lenschow, D. H., and LeMone, M. A.: 1978, 'The TemperatureHumidity Covariance Budget in the Convective Boundary Layer', J. Atmos. Sci. 35, 47-58. 